\title{
The residence time of the water in Lago Maggiore (N. Italy): first results from an Eulerian-Lagrangian approach
}

\author{
Leonardo CASTELLANO*, Walter AMBROSETTI ${ }^{1)}$, Luigi BARBANTI ${ }^{1)}$ and Angelo ROLLA ${ }^{1)}$ \\ Matec Modelli Matematici, Via Rondoni 11, 20146 Milano, Italy \\ ${ }^{1)}$ CNR Institute for Ecosystem Study, Largo V. Tonolli 50, 28922 Verbania-Pallanza, Italy \\ *e-mail corresponding author: matec_srl@iol.it
}

\begin{abstract}
The paper describes a numerical study for estimating the spatial distribution of the hydraulic residence time in Lago Maggiore. A $3 D$ eulerian time-dependent CFD code has been applied under real conditions, taking into account the effects of the monthly mean values of the mass flow rates and temperatures of all the tributaries, mass flow rate of the Ticino effluent and meteorological, hydrogeological and limnological parameters available from the rich data-base of CNR-ISE (Pallanza). The velocity distributions from these simulations were used to compute the paths of a number of massless markers with different initial positions and so evaluate their residence times within the lake. The results presented here follow a two-year simulation and show encouraging agreement with the mechanisms of mixing and of deep water oxygenation revealed by recent limnological studies carried out at CNR-ISE. Further studies are in progress to improve the results and extend the research over a time period of at least four years.
\end{abstract}

Key words: residence time, hydro-meteorological parameters, eulerian mathematical model, CFD, lagrangian markers

\section{INTRODUCTION}

An inspection of the technical literature reveals that various concepts of time scale designed to characterize transport phenomena in rivers, lakes and estuaries emerge from research and studies on the quality of the water in these ecosystems.

While essentially four different names (Residence Time, Transit Time, Age, Flushing Time) are used in (a range of) papers and reports, the same name quite often refers to parameters indicating dissimilar sets of physical or physical-chemical mechanisms and/or different approaches and experimental procedures.

The need to remove this confusion was first highlighted more than 30 years ago by Bolin \& Rodhe (1973), but it is only in recent years that sufficient attention has been devoted to the problem, e.g. by Monsen et al. (2002) and Ji (2008). Definitions have consequently become increasingly detailed and precise, and at the same time the intrinsic difficulties of the problem and the causes of the unavoidable approximation of the solutions have become even clearer (Shelton \& Alber 2002; Waugh et al. 2002; Ambrosetti et al. 2003; Rueda \& Cowen 2005; Delhez \& Deleersnijder 2006; Oliveira 2006; Doos \& Engqvist 2007; Lucas et al. 2009).

Many of the difficulties involved in giving good estimations even for a theoretically well-defined parameter lie in the complexity of executing (and correctly interpreting) adequate experimental observations and measurements on systems that strongly interact with the atmosphere and surrounding aquatic environments.
These difficulties can be particularly severe for large natural water bodies with a long evolution time: apart from the material costs, any extreme meteorological event may destroy instruments, interrupt the acquisition of data, and even change the scenarios (a typical example is the dramatic variation in the sections measuring the discharge of tributaries and effluents provoked by high intensity rainfall).

One way of overcoming these difficulties or of complementing other studies is the increasing use of CFD (Computational Fluid Dynamics) to evaluate the timescale parameters of natural water bodies (Loga-Karpinska et al. 2003; Shen \& Haas 2004; Jouon et al. 2006; Wilde et al. 2006; Liu et al. 2008).

The application of this approach rests on the assumption that the interactions between a water body and the external environment are only one-way (from the latter to the former) and these interactions (in the case of lakes: mass flow rate and temperature of the inflows/outflow, rain, runoff, wind, heat exchange with the atmosphere) can be described using a relatively small number of known parameters or functions which represent a statistically valid description of the time behaviour of the external phenomena over a fairly long period.

A second indispensable precondition is the use of a well-tested computer code that has been proven to give satisfactory results over multiple spatial and time scales and boundary conditions.

The aim of this paper is to explain the guidelines of a campaign of numerical simulations devised to estimate the time scales of the hydrodynamics and transport 
phenomena of Lago Maggiore and through them to compile a detailed spectrum of the renewal times of its water.

\section{BACKGROUND OF THE PRESENT STUDY}

Studies of applied limnology by today's scientific community can be divided into two broad areas: those focused on developing the knowledge required to preserve and/or improve the health of lakes, and those that study lakes to find evidence of the climate change phenomenon.

In the first case, the lake is treated as a large biochemical reactor in which the degree of development of the biochemical phenomena depends mainly on the ratio between the Hydraulic Residence Time and the rate of the reactions (in addition to temperature and turbulent mixing); in the second, it is regarded like a patient showing symptoms which are suspected of originating in some historical anomalies (for instance, traces of these anomalies are clearly seen in the "Climatic Memory" of the great subalpine lakes; Ambrosetti \& Barbanti 1999; Ambrosetti \& Sala 2008).

In both cases a sufficiently reliable estimate of the Hydraulic Residence Time is required; this would also be used as a reference value for other time scales that could take into account other mechanisms apart from that of pure motion, such as chemical or biochemical decay, turbulent diffusion, macroscopic dispersion, adsorption, colonization, sedimentation and so on.

Focusing on lakes, as a first approximation the theoretical value of the Hydraulic Residence Time, here indicated by the symbol $\tau_{H}$, can be calculated by the relation:

$$
\tau_{H}=V / \dot{Q}
$$

where $\dot{Q}$ is the annual amount of water passing through the water body and $V$ the volume of the whole basin.

This is rather a rough definition, since it assumes the lake to be similar to a large river, morphologically uncomplicated, in which the velocity field is almost uniform and the most important physics of the seasonal cycle are absent. In contrast, in the course of their annual cycle the deep lakes show differentiated vertical thermal structures which, depending on geographical, climatic and morphological conditions, give rise to one or more periods of vertical thermal stratification during which the thickness of the layer involved in the water renewal, i.e. the layer mixed at the surface, represents only a more or less large percentage of the whole water mass. Of course, many other factors influence the riverlake-river hydrological complex; of these, a considerable role is played by the system of currents and other movements arising in the lake, the topography of the bed, and the morphology of the basin, which is very often highly irregular due to the presence of bays and lateral arms only marginally involved in the general dynamics of the lake.
As far as Lago Maggiore and other great lakes of the northern temperate zone are concerned, the relatively small thickness of the layer involved in the vertical mixing by convection of the waters at the end of the limnological winter is of decisive importance. As shown by Ambrosetti \& Barbanti (2002), the reduction of the deep recirculation is a consequence of the climate change of the last decades, which has prevented the homogenization of the water column and its density with a related increase in vertical stability. In fact, the measured data reveal that the waters of the deep hypolimnion are practically isolated from the upper part of the lake and have almost no possibility of renewal.

All the above facts prompted the promotion of a campaign of numerical simulations designed to permit a more realistic and more detailed evaluation of renewal times.

Many approaches have been developed in the field of mathematical modelling to improve the accuracy of the assessments. For instance, George \& Harley (2003), suggested computing a residence time for each day of the year by using the average lake volume for certain months, the average epilimnetic volume for the others and the daily volume of water entering the lake; the algorithm is applied in "hindcast" mode to prove that the model is reliable for predicting future conditions. Conceptually similar, but computationally more sophisticated, is a previous model devised by Rossi et al. (1975) for monomictic lakes, based on the same physical assumptions adopted by Piontelli \& Tonolli (1964) for Lago Maggiore, i.e., a) the outflow mass fluxes come only from the most superficial layers; b) the inflow mass fluxes mix homogeneously only with the waters above the epilimnion in the summer and with the mixed layer in the winter. The application of this model to Lake Lugano revealed differences up to one order of magnitude between the water renewal times in different zones of the lake, thus pointing out the incorrectness of defining a single value of hydraulic residence time for the whole water body.

Nowadays there is a widespread awareness of the need to assess more than one value for this parameter of pure hydraulic nature; and more subtle levels of analysis can be achieved by trying to describe the effects of the spatial scale and seasonal conditions. Efforts to reach this objective have resulted in the introduction of more meaningful theoretical definitions and an improvement in methods of measuring the relevant parameters.

This aspect has already been discussed in the previous section and will not be repeated here. It will be more useful to summarize the assumptions underlying the use of one or more sets of equations implemented in a CFD computer code. There follow a number of considerations complementary to some of those reported by Loga-Karpinska et al. (2003).

The central equations of a CFD code represent the laws of conservation of the total mass, momentum and 
energy of a fluid system, and generally have a structure similar to that of the basic Navier-Stokes equations, Bird et al. (1960).

$$
\begin{gathered}
\frac{\partial \rho}{\partial t}+\nabla \cdot(\rho \underline{u})=0 \\
\frac{\partial \rho \underline{u}}{\partial t}+\nabla \cdot(\rho \underline{u} \underline{u})=-\nabla p-\nabla \cdot \underline{\tau}+\rho \underline{g} \\
\frac{\partial \rho C_{p} T}{\partial t}+\nabla \cdot\left(\rho C_{p} T \underline{u}\right)=-\nabla \cdot \underline{q}
\end{gathered}
$$

When coupled with the initial conditions (specifying the state of the system at the virtual time 0.0) and the necessary and sufficient boundary conditions for describing physical interactions with the surrounding environments and closing the mathematical problem, these equations (Eulerian approach) provide in principle a satisfactory description of the temperature and velocity field at any desired point in space or time of the water body under consideration.

With regard to Residence Time, the solutions of these equations by themselves can only provide a single global value more or less equal to the one produced by eq. (1), but they make it possible to extract estimates in principle at any level of detail, by introducing Lagrangian equations of motion of a certain number of massless particles travelling at the computed local and instantaneous velocity of the water. These Lagrangian equations can be written as:

$\underline{x}_{p}\left(\underline{x}_{0, p}, t_{0, p} ; t\right)=\underline{x}_{0, p}+\int_{t_{0, p}}^{t} \underline{u}\left(\underline{x}_{p} ; \tau\right) d \tau \quad, \quad p=1,2, \ldots ., N_{p}$

The Hydraulic Residence Time of the particle p, which is identified only by its initial position $\underline{x}_{0, p}$ and time instant $t_{0, p}$ at which it entered the lake, is assumed to be given by $t_{p, o u t}-t_{0, p}$ where $t_{p, \text { out }}$ is the time at which the position $\underline{x}_{p}$ definitively falls inside the outflow section of one of the effluents.

The various possibilities of analysis offered by this approach may be easily understood. For instance, a group of particles can be associated to the inflow of each of the tributaries, and then the residence time of each of them can be deduced by a statistical analysis of the different ensembles of the $t_{p, \text { out }}$ values.

To complete this discussion, we should also take into consideration the CFD simulations of tracer experiments with hydrosoluble substances. In this case, it makes no difference whether the operation is one of continuous or pulse injection, the Eulerian approach consists in associating to eq. (2)-(4) a convective/diffusive equation like the following:

$$
\frac{\partial \rho \omega}{\partial t}+\nabla \cdot(\rho \underline{u} \omega)=\nabla \cdot(\Gamma \nabla(\rho \omega))
$$

Two data can be deduced from the numerical solution of the above equation: the time at which the tracer arrives at an outflow section of the water body, and/or the mean value of the "effective" residence time (computing the first moment of the time evolution of the rate of tracer mass loss). In many papers this last parameter (or distribution of parameters) is referred to as "age" (Loga-Karpinska et al. 2003; Rueda \& Cowen 2005; McGuire \& McDonnell 2006; Herman et al. 2007). For the present discussion we prefer to use the qualifying term "effective", to emphasize that a mass tracer particle always travels faster than a massless marker owing to the additional diffusion force described by the last term on the right of eq. (6), which also takes into account the effects of the turbulent regime of a natural water body.

Finally, two further remarks are in order. First, eq. (6) remains valid for any hydrosoluble, non-reacting substance; a differentiation is possible only when the influence on the mass density of the aqueous solution is taken into account, thus strongly increasing the complexity of the mathematical and numerical model. Second, in the case of reactive materials, the effective residence time depends upon the (chemical and/or biochemical) kinetics of creation or decay of the substance, so that to the right of the equal sign of eq. (6) there must be added a more or less sophisticated source term that takes account of these fundamental effects. In the most complex situations, all the reacting species present in the aquatic ecosystem have to be take into account, giving rise to a formidable theoretical and numerical problem.

\section{THE MATHEMATICAL MODEL FOR THIS STUDY}

The CFD code used for this study, devised to analyze the mechanisms governing the seasonal cycle of thermal stratification and destratification in Lago Maggiore, the structure of the velocity fields and the spectrum of the residence times of waters at different depths, has been described in detail in a recent paper by Castellano et al. (2008). It consists of an upgraded version of an original mathematical model formulated more than 30 years ago (Castellano et al. 1977; Dinelli \& Tozzi 1977). Although of simple structure and semiempirical nature, the turbulence models originally implemented in the computer code have been left unchanged in the restructuring process because of their long history of validation and applications to real systems.

As shown in figure 1, a water body is assumed to be divided into $L$ finite horizontal layers for which the equations shown in tables $1 \mathrm{a}$ and $1 \mathrm{~b}$ are valid.

Water density as function of temperature and salinity is given by $\left(T\right.$ in ${ }^{\circ} \mathrm{C}, s$ in ppt):

$$
\rho=\frac{\rho_{1}(T)}{\rho_{2}(T)}+\rho_{3}(T, s)
$$




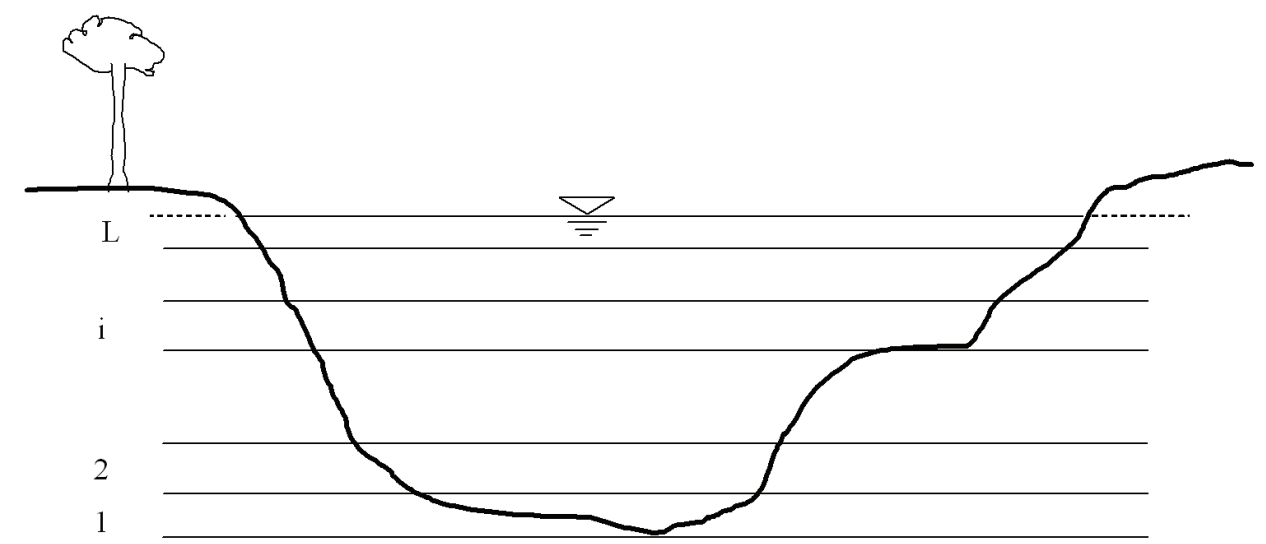

Fig. 1. Scheme of a multilayer discretization of the lake.

Tab. 1a. Governing equations for the inner layers.

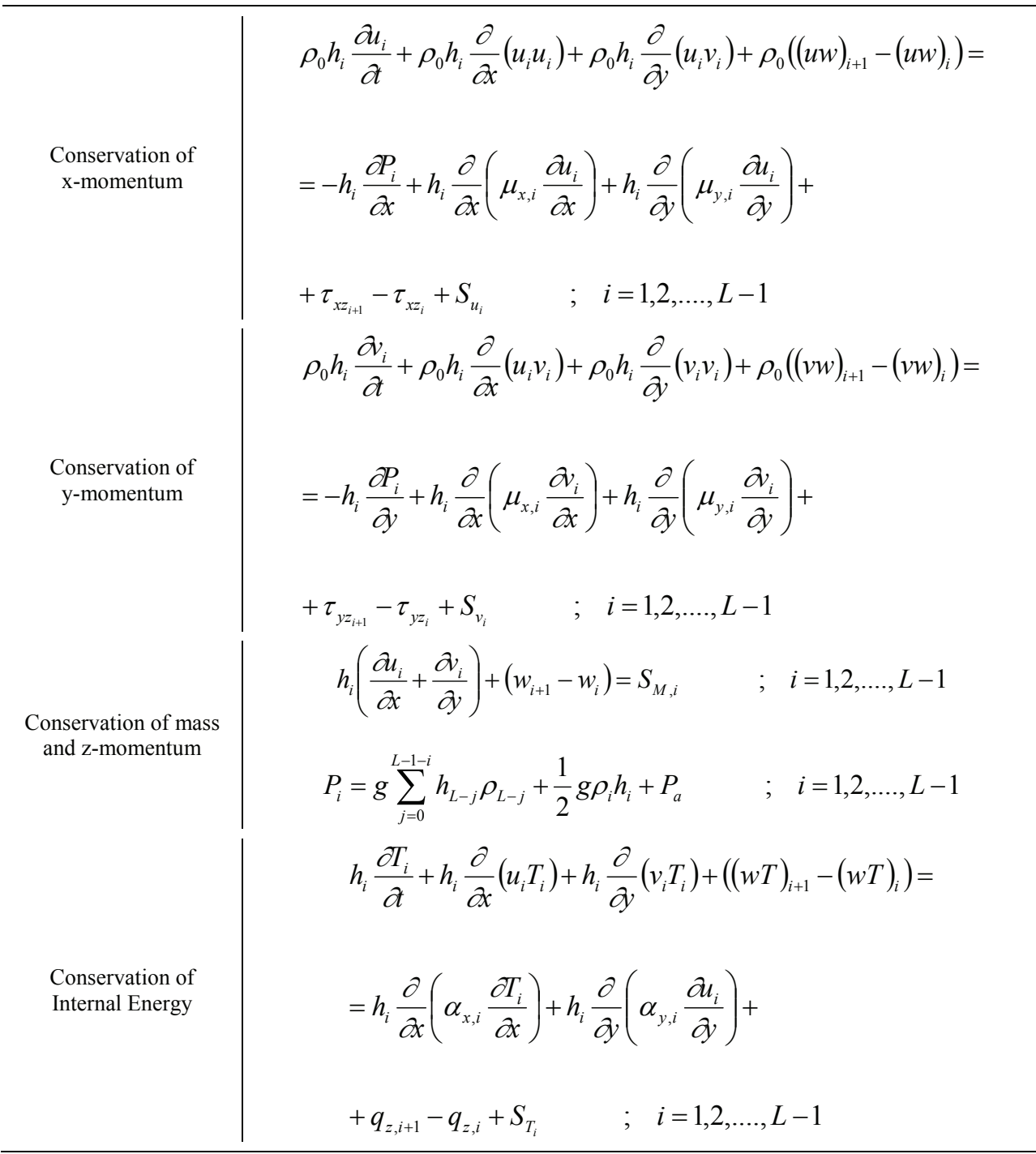


Tab. 1b. Governing equations for the free surface layer.

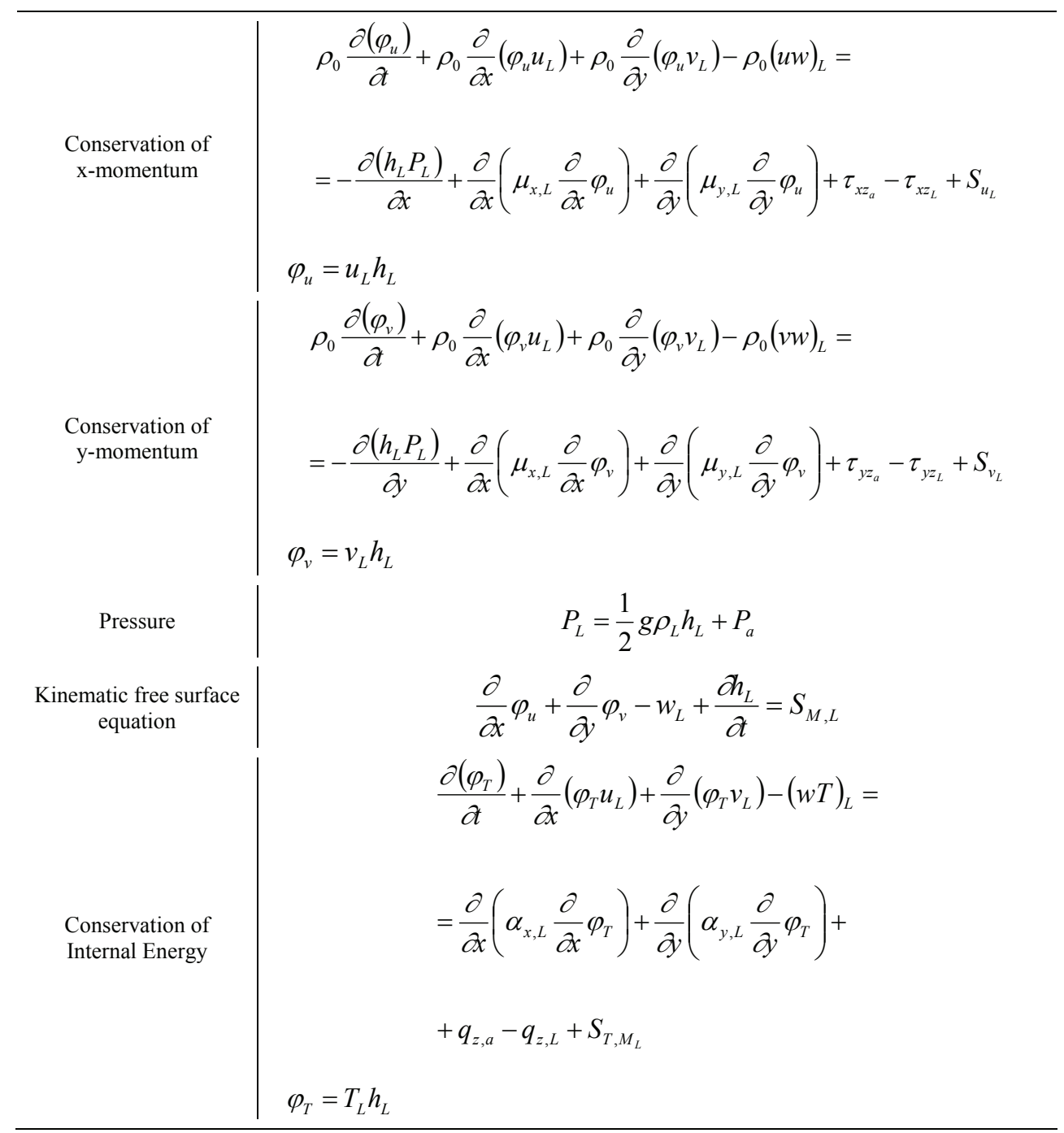

$$
\begin{gathered}
\rho_{1}(T)=999.84152+\sum_{i=1}^{5} a_{i} T^{i} \\
\rho_{2}(T)=1 .+b_{1} T \\
\rho_{3}(T)=c_{1} s+c_{2} s^{1.5}+c_{3} s^{2}
\end{gathered}
$$

with the coefficients defined as in Martin \& McCutcheon (1999).

Details of the approximations and assumptions made to describe turbulence and mass, momentum and heat exchange with the external environment (i.e., the explicit forms of parameters $\rho, \mu_{x}, \mu_{y}, \alpha_{x}, \alpha_{y}$ and terms $\left.S_{M_{L}}, S_{T}, S_{u}, S_{v}, \tau_{x z}, \tau_{y z}, q_{z}\right)$ can be found in Castellano et al. (1977, 2008), Dinelli et al. (1977). The numerical solution of the above equations is obtained by means of an implicit and iterative algorithm imple- mented in a Finite Volume discretization method (Castellano et al. 1977, 2008; Dinelli et al. 1977).

The trajectories of the massless markers are updated in time by equations such as:

$$
\underline{x}^{t+\delta t} \equiv\left\{\begin{array}{l}
x_{p}^{t+\delta t}=x_{p}^{t}+\vec{u}\left(\underline{x}_{p}^{t}, t+\delta t\right) \delta t \\
y_{p}^{t+\delta t}=y_{p}^{t}+\bar{v}\left(\underline{x}_{p}^{t}, t+\delta t\right) \delta t \\
z_{p}^{t+\delta t}=z_{p}^{t}+\bar{w}\left(\underline{x}_{p}^{t}, t+\delta t\right) \delta t
\end{array}\right.
$$

which represent the discrete counterpart of equation (5); $\delta t$ is the time increment for the current time step and $\bar{u}$, $\bar{v}, \bar{w}$ denote mean values of the updated water velocity components around the position of the particle at the previous time instant. 


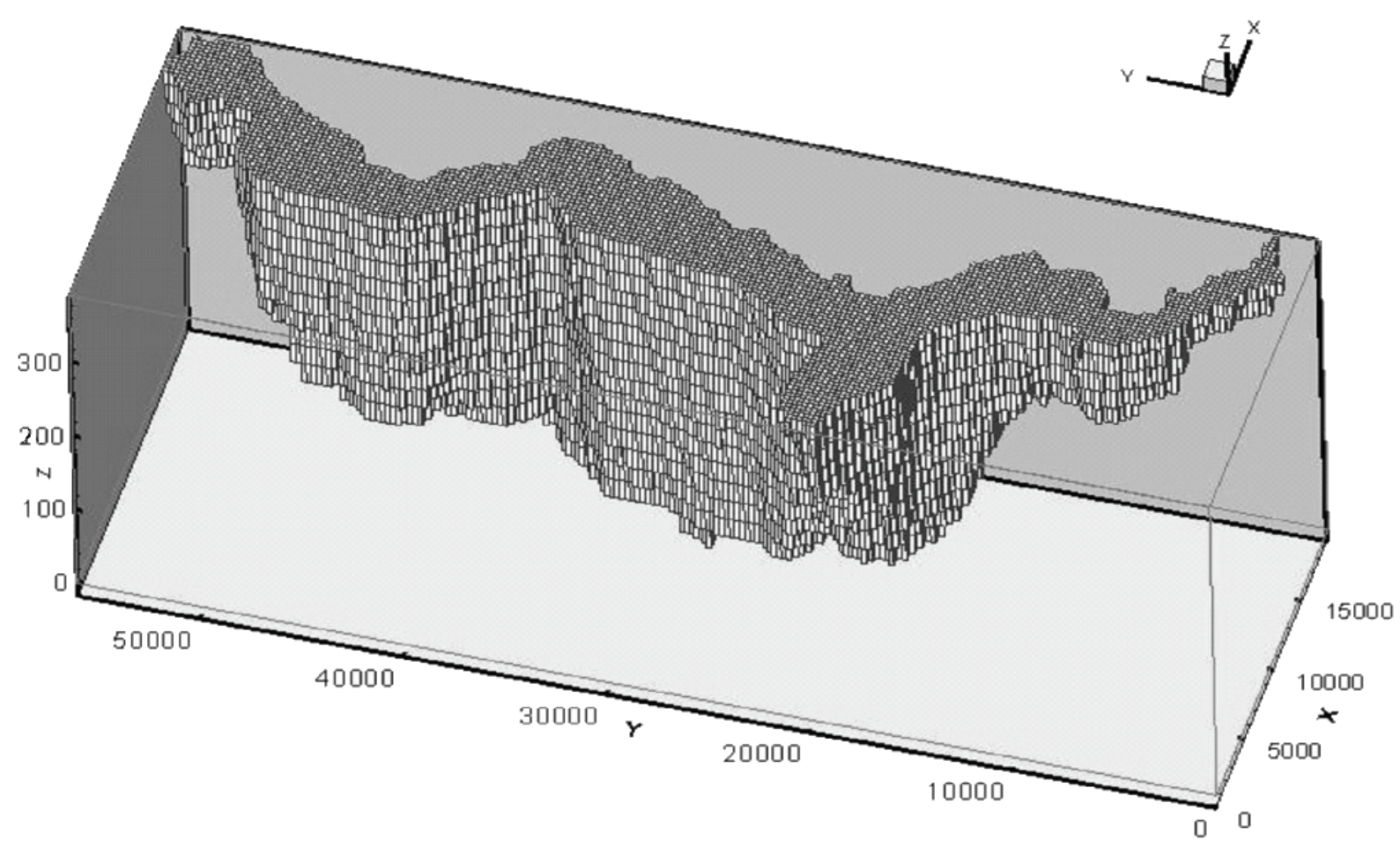

Fig. 2. Grid mesh over the entire geometry of Lago Maggiore used in the present study (unit: m).

\section{DISCRETE MODEL AND BOUNDARY CONDITIONS}

The discrete model of the lake used for the present study is shown in figure 2; it consists of 50 horizontal layers subdivided into square blocks of $250 \times 250$ meters. The height of the layers decreases from bottom to top and the total number of computational cells is 877,500 .

As can be seen in the figure, the longitudinal coordinate $\mathrm{Y}$ is positive from South to North, with its origin located at the incile of the lake; the transverse coordinate $\mathrm{X}$ is positive from West to East, with its origin located at the mouth of the River Toce; finally, the vertical coordinate $\mathrm{Z}$ has its zero point at maximum depth and increases from bottom to top.

The boundary conditions (i.e., the contributions of mass, momentum and heat exchange with the external environments) were computed using the monthly mean values of the large mass of data collected for many years by CNR-ISE through continuous monitoring of the meteorological, hydrogeological and limnological conditions of Lago Maggiore and its catchment area:

- mass flow rate and temperature of tributaries;

- mass flow rate of the River Ticino emissary;

- meteoric precipitations and their temperatures (computed);

- flow by runoff and its temperature (computed);

- vertical profiles of temperature of the lake;
- strength and direction of the wind;

- all the meteorological parameters which affect the heat exchange mechanisms through the free surface (air temperature and vapour pressure; fraction of cloud cover, short-wave solar radiation, long-wave radiation from sun and atmosphere, long-wave radiation emitted/reflected from the lake).

As discussed in many papers (and from different decades: Anderson 1954; Huber et al. 1972; Laval et al. 2003; Leon et al. 2006), this large number of parameters can be processed using algorithms and empirical correlations of various levels of sophistication; from the point of view of the multidimensional CFD, the key-point of this operation is to reduce as far as possible the number of really indispensable data and sub-models while preserving the actual overall heat balance.

Before starting the numerical campaign described in this paper, a lot of time was spent opening a dialogue between the computer code and the lake. Thus a series of numerical runs were executed to study step-by-step the responses of the water body to various hydro-dynamic, thermal and meteorological loads, using the results of each simulation to try to foresee the output of the next, more complex, one, and analyze the possible causes of eventual unexpected differences.

The above activity allowed us to:

a) acquire sensibility toward the main phenomena which have a role in lake hydrodynamics; 


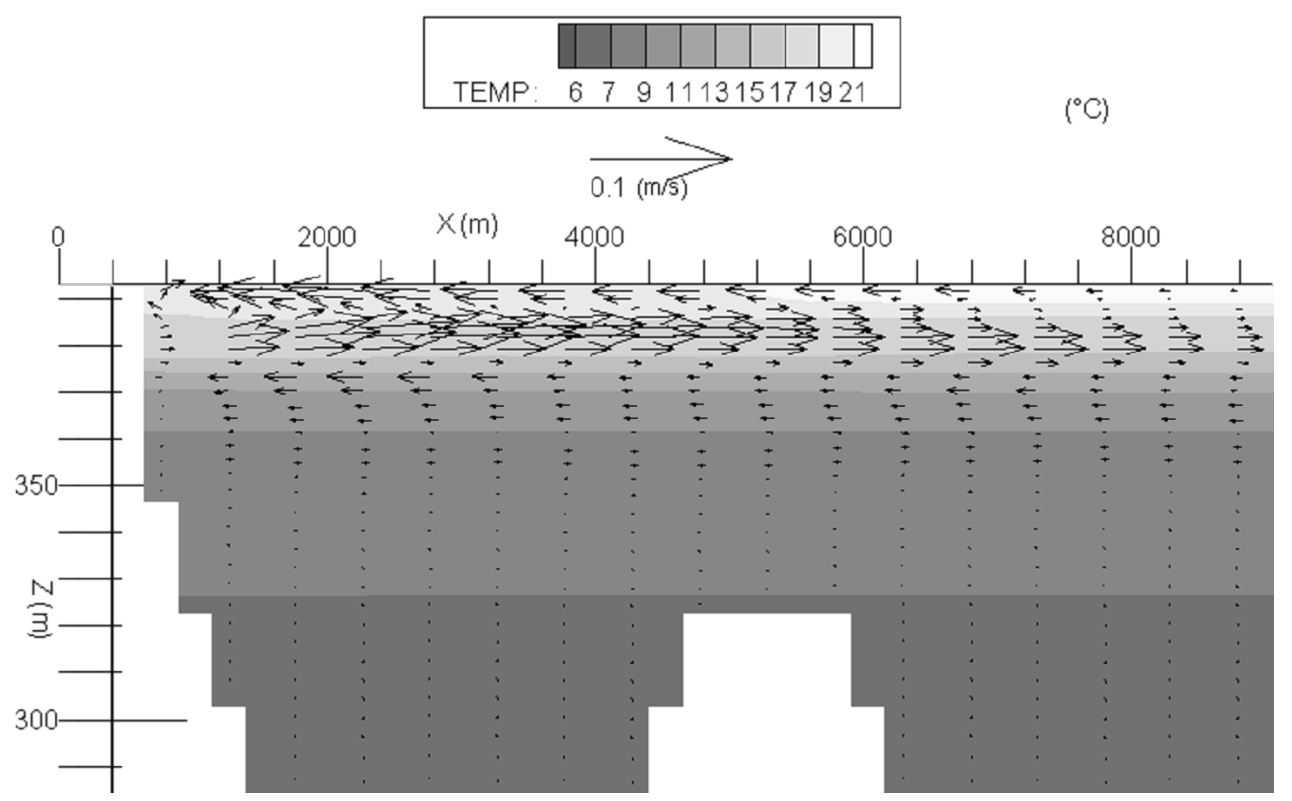

Fig. 3. Temperature distribution and flow pattern in the upper portion of the $\mathrm{XZ}$ cross section $19.5 \mathrm{~km}$ from South (end of June 2002).

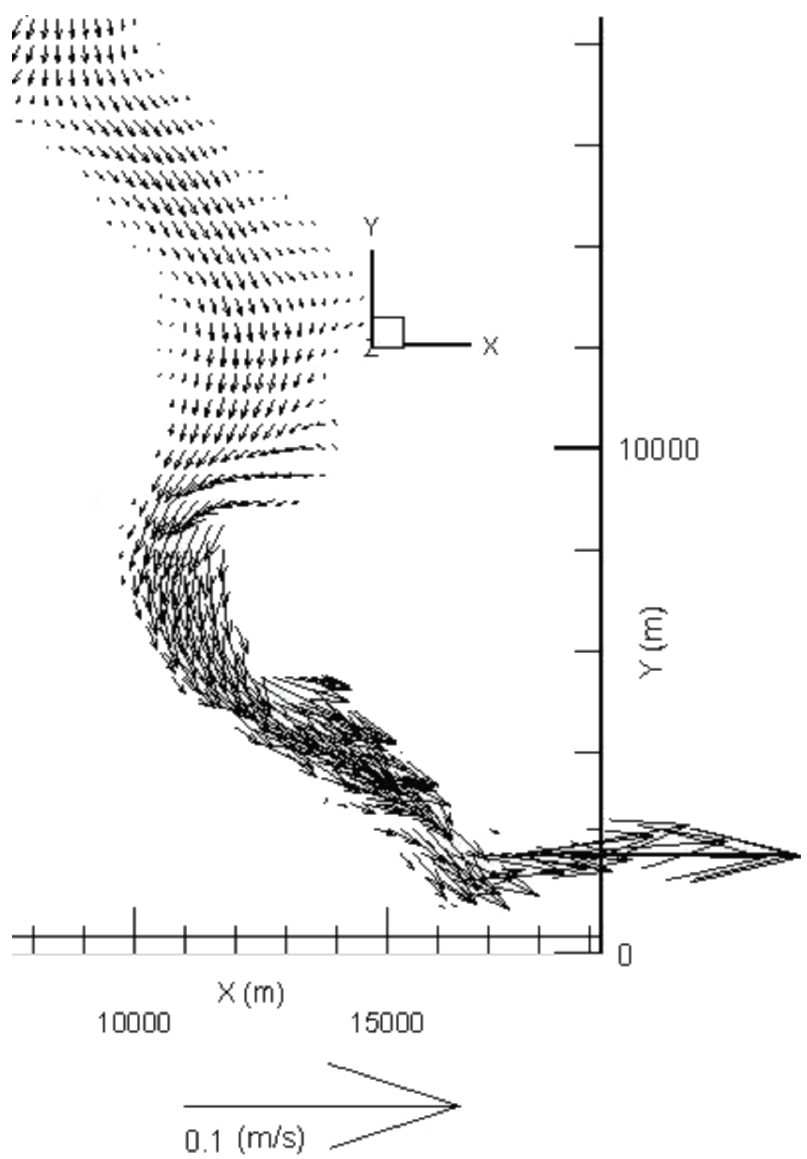

Fig. 4. Flow pattern at the free surface of the southern region of the lake (end of June 2002). b) find out what kind of global mean parameters can be extracted from the enormous population of numbers generated by a 3D simulation and choose the most useful and significant for the management of the lake;

c) compare flow and thermal patterns from the simulations with the results of experimental campaigns over different spatial and time scales and with the conceptual schemes of the seasonal cycles available from the studies performed by ISE-CNR;

d) establish a reasonable level of approximation (as simple as possible - as sophisticated as necessary) in the description of the hydro/meteo input parameters.

\section{RESULTS OF A TWO-YEAR SIMULATION}

The output of a computer code like the one used in the present study consists of many millions of numbers for each time step, from which can be extracted information about the physical behaviour of the lake in any desired zone at any spatial scale. Some examples are shown in figures $3,4,5,6$.

The criteria utilized to evaluate the general likelihood of the results of the simulations were based on the degree of agreement between the computed and the measured velocities and vertical profiles of temperature (Barbanti \& Carollo 1965; Ambrosetti et al. 2007). As regards the temperature, some comparisons are shown in figure 7 and give a correct idea of the different levels of precision reached for the different months of the year. Considering the order of magnitude of the time and spatial dimensions of the system, the overall result may be regarded as satisfactory. However, a detailed analysis 


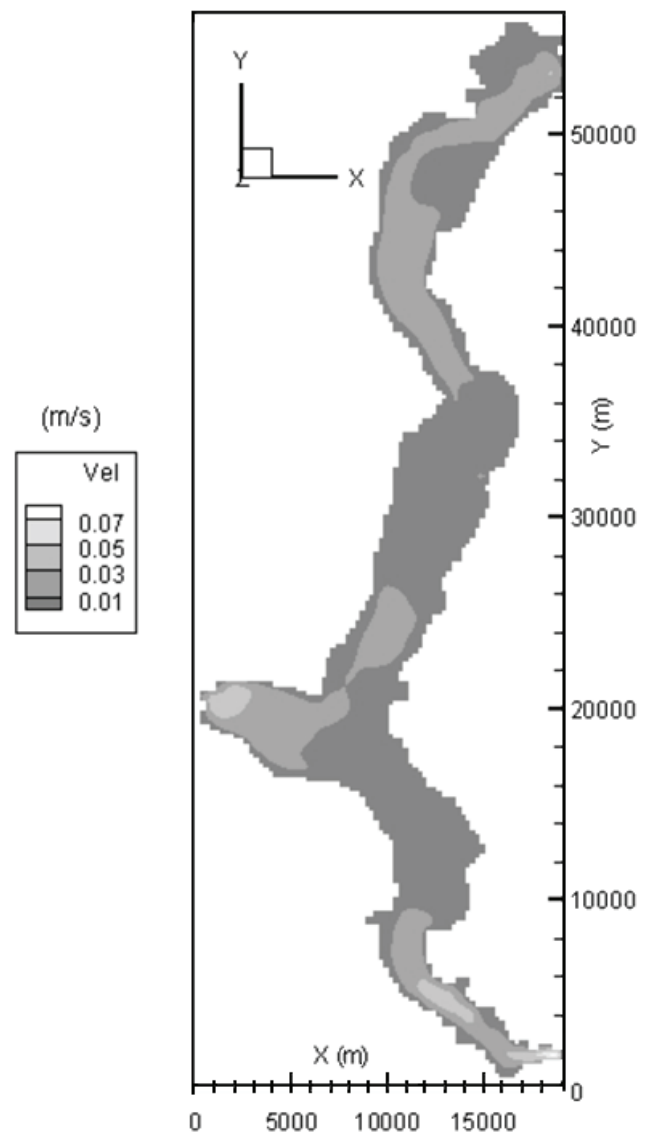

Fig. 5. Distribution of the modulus of velocity at the free surface (end of June 2002).

of the modelling and numerical reasons for the causes of major differences, and methods for further improvement in this direction, is the subject of a research activity currently in progress. As for the velocity fields, general agreement has been found in terms of the order of magnitude of the punctual values available from measurements and a substantially perfect similitude between the macro-recirculations.

In the context of this study the above results are reported solely to quantify the capabilities of the computer code. Our main aim is to discuss the fate of 72 massless Langrangian markers placed in different positions in the lake at zero time of a multiannual simulation.

As tables 2 and 3 show, two types of markers were considered: "environmental markers", which had their starting position inside the lake, and "tributary markers", whose starting position was at the mouth of the various tributaries. Note that the first 31 environmental markers were placed at different depths in the northernmost area of the lake, close to the outflow of the River Ticino into the lake, while the others were placed at increasing depths going in a southerly direction.

Figures $8 \mathrm{~A}-8 \mathrm{E}$ show the projection on the XY plane of the trajectories traced by some of the above markers

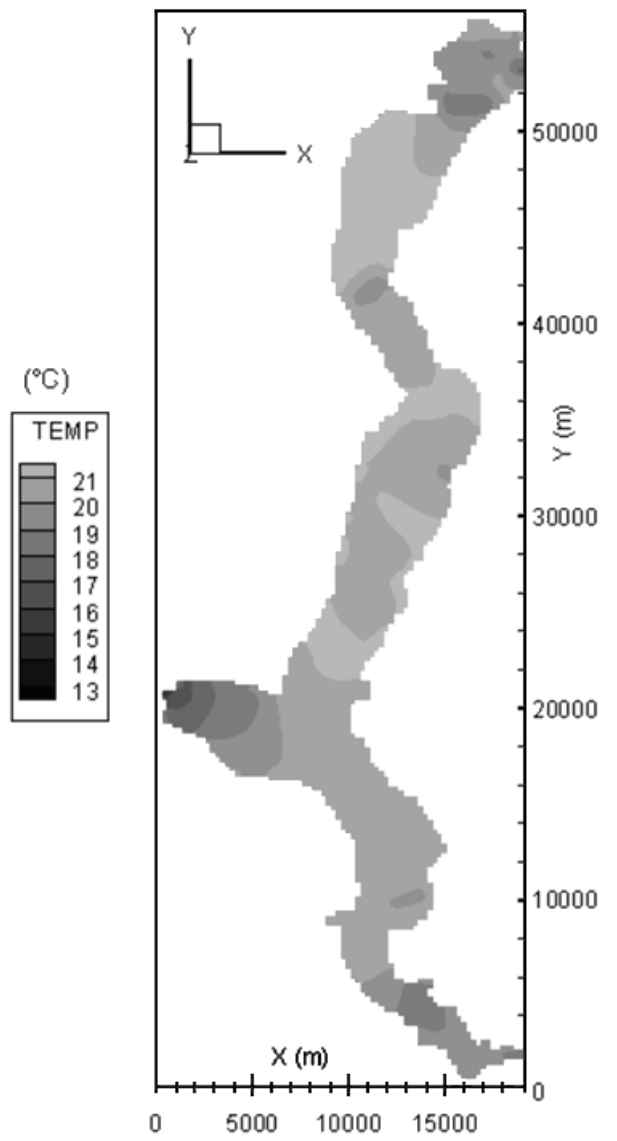

Fig. 6. Distribution of temperature at the free surface (end of June 2002).

over a period of 2 years and the corresponding vertical movements.

The following observations can be made from the overall set of results.

1) Only 5 of the 31 environmental markers (M5, M8, M10, M19, M31) with a starting position near the mouth of the inflowing Ticino have reached the area of the outflowing Ticino and so may be regarded as having exited the lake. The resulting residence time values are between around 350 days (for the particles which started only a few metres below the free surface) and around 500 days (for the particles with a deeper starting position). Of those reaching the outflow, marker M5, which left at the level of Locarno at a depth of $9.0 \mathrm{~m}$ (Tab. 2) followed a sinuous course, initially moving towards the western part of the lake before continuing towards the outflow. In the first 320 days it stayed at a depth within the top $20 \mathrm{~m}$, subsequently rising to the surface before exiting the lake after around 500 days.

The exception in this series of markers was M31, which, starting from a depth of $-100 \mathrm{~m}$, succeeded in rising to the surface after a year, when it was located at the level of the deepest part of the lake (Ghiffa), subse- 

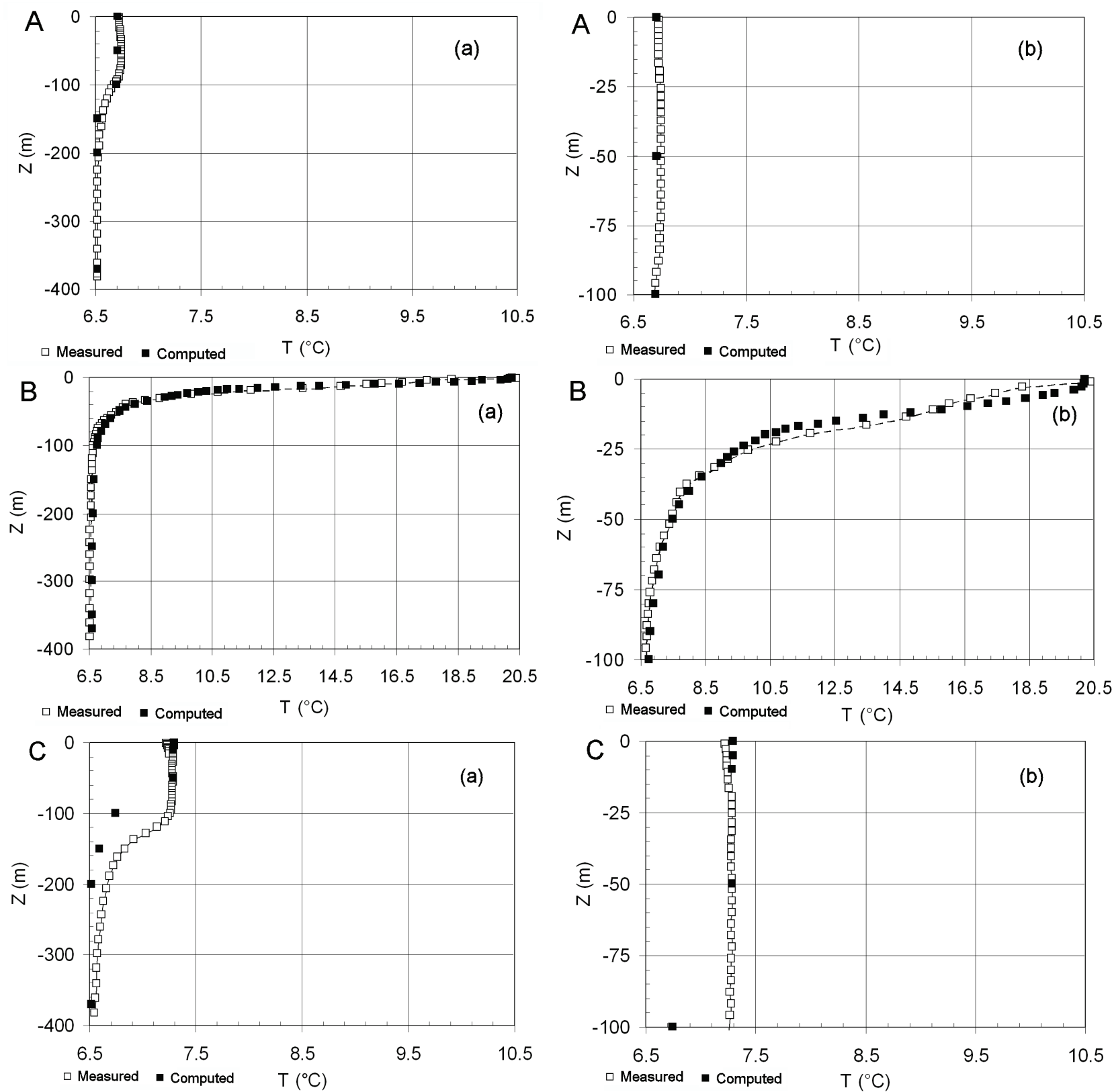

Fig. 7. Vertical profile of the mean temperature of Lago Maggiore. A: end of January 2002; B: end of June 2002; C: end of December 2002; (a): layer 0-max depth; (b): layer 0-100 m.

quently exiting. The rise of this marker to the top may be connected with the fact that at the beginning of the two-year period (winter 2001-2002) the vertical convective mixing had reached a depth of only $100 \mathrm{~m}$, so that the marker remained in its starting position for the whole of the annual cycle. The next winter the winter mixing exceeded a depth of $120 \mathrm{~m}$, reaching the marker and carrying it up towards the surface.

Interestingly, the surface markers exiting the lake all had a tendency to move towards the western shore. This appears to be due not so much to an effect of the Coriolis force (negligible if we consider the relatively narrow width of the lake) as to the distinctive morphology of the lake valley, which tends to force the north winds (locally the strongest) to blow in a SSW direction.

2) The 26 remaining particles in this series, which started out with almost the same horizontal coordinates and a vertical position between -1 and $-128.5 \mathrm{~m}$, followed different routes: M17, M22, M24, M30 travelled up and down over a relatively extensive area of the lake before returning almost to their initial position; M25 was lost, exiting from the calculation domain (this can be regarded as an undesired numerical effect); all the others covered around half of the whole nominal NorthSouth distance, sometimes rising towards the free surface, sometimes sinking towards the bottom, and sometimes floating freely at their initial depth. 
Tab. 2. Starting positions of environmental markers.

\begin{tabular}{|c|c|c|c|c|c|c|c|}
\hline Markers & $\mathrm{X}(\mathrm{m})$ & $\mathrm{Y}(\mathrm{m})$ & $\mathrm{Z}(\mathrm{m})$ & Markers & $X(\mathrm{~m})$ & $\mathrm{Y}(\mathrm{m})$ & $\mathrm{Z}(\mathrm{m})$ \\
\hline M_1 & 16875. & 55375. & -1.0 & M_26 & “” & “"” & -80.0 \\
\hline M_2 & “"” & “"” & -3.0 & M_27 & “"” & “" & -84.0 \\
\hline M_3 & "” & “" & -5.0 & M_28 & “" & “” & -88.0 \\
\hline M_4 & “"” & “"” & -4.0 & M_29 & “"” & 54625. & -92.0 \\
\hline M_5 & “"” & “"” & -9.0 & M_30 & “"” & “"” & -96.0 \\
\hline M_6 & “" & “" & -11.0 & M_31 & “"” & “"” & -100.5 \\
\hline M_7 & “” & “” & -13.5 & M_32 & 12375. & 50500 . & -106.0 \\
\hline M_8 & “” & “” & -16.5 & M_33 & “"” & “"” & -112.0 \\
\hline M_9 & “"” & “"” & -19.5 & M_34 & “" & “"” & -120.0 \\
\hline M_10 & “"” & “"” & -22.5 & M_35 & “"” & "” & -128.0 \\
\hline M_11 & 16625. & 55375. & -25.5 & M_36 & “” & “” & -138.0 \\
\hline M_12 & “"” & “"” & -25.5 & M_37 & "' & 50000 . & -150.0 \\
\hline M_13 & 16875. & 55375. & -28.5 & M_38 & “"” & “"” & -162.0 \\
\hline $\mathrm{M}_{-}^{-} 14$ & “"” & “"” & -34.5 & M_39 & “"” & “"” & -174.0 \\
\hline M_15 & “"” & “” & -37.5 & M_40 & 12875. & 49125. & -189.0 \\
\hline M_16 & “" & “" & -40.5 & M_41 & “"” & “"” & -207.0 \\
\hline M_17 & “"” & “” & -44.0 & M_42 & 12625. & 47275 . & -225.0 \\
\hline M_18 & “” & “"” & -48.0 & M_43 & “"” & “"” & -243.0 \\
\hline M_19 & “"” & 55125. & -52.0 & M_44 & 11375. & 46875. & -261.0 \\
\hline M_20 & “" & “"” & -56.0 & M_45 & “"” & “"” & -279.0 \\
\hline M_21 & “” & “” & -60.0 & M_46 & 10875. & 44125. & -298.5 \\
\hline M_22 & “” & 54875. & -64.0 & M_47 & 12875 . & 39125. & -319.5 \\
\hline M_23 & “"” & “” & -68.0 & M_48 & “” & “” & -340.5 \\
\hline M_24 & “"” & “" & -72.0 & M_49 & 14875. & 36375. & -361.5 \\
\hline M_25 & “"” & “" & -76.0 & M_50 & “"” & 35625. & -370.00 \\
\hline
\end{tabular}

Tab. 3. Staring positions of tributary markers.

\begin{tabular}{|c|c|c|c|c|c|c|c|c|c|}
\hline Markers & River & $\mathrm{X}(\mathrm{m})$ & $\mathrm{Y}(\mathrm{m})$ & $\mathrm{Z}(\mathrm{m})$ & Markers & River & $\mathrm{X}(\mathrm{m})$ & $\mathrm{Y}(\mathrm{m})$ & $\mathrm{Z}(\mathrm{m})$ \\
\hline M 51 & Ticino & 18875. & 53375. & -1.0 & M 62 & Canobino & 9375. & 42875.0 & -7.0 \\
\hline M_52 & “" & 18875. & 53375. & -7.0 & M_63 & Maggia & 14875. & 51375.0 & -1.0 \\
\hline M_53 & Vevera & 11875. & 4875. & -1.0 & M_64 & & 14875. & 51375.0 & -7.0 \\
\hline M_54 & “"” & 11875. & 4875. & -7.0 & M_65 & Verzasca & 18625. & 55125.0 & -1.0 \\
\hline M_55 & Erno & 10625. & 9625. & -1.0 & M_66 & “" & 18625. & 55125.0 & -7.0 \\
\hline M_56 & “"” & 10625. & 9625. & -7.0 & M_67 & Tresa & 15125. & 32375.0 & -1.0 \\
\hline M_57 & Toce & 875. & 20875. & -1.0 & M_68 & “"” & 15125. & 32375.0 & -7.0 \\
\hline M_58 & “"” & 875. & 20875. & -7.0 & M_69 & Boesio & 10875. & 21125.0 & -1.0 \\
\hline M_59 & S.Bernard. & 7125. & 22125 . & -1.0 & M_70 & “"” & 10875. & 21125.0 & -7.0 \\
\hline M 60 & & 7125. & 22125 . & -7.0 & M 71 & Bardello & 12875. & 14875.0 & -1.0 \\
\hline M 61 & Cannobino & 9375. & 42875 . & -1.0 & M_72 & & 12875. & 14875.0 & -7.0 \\
\hline
\end{tabular}




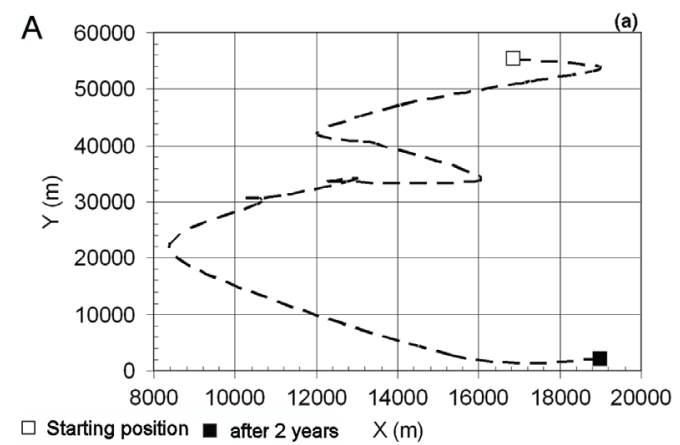

$\square$ Starting position $\square$ after 2 years $X(\mathrm{~m})$
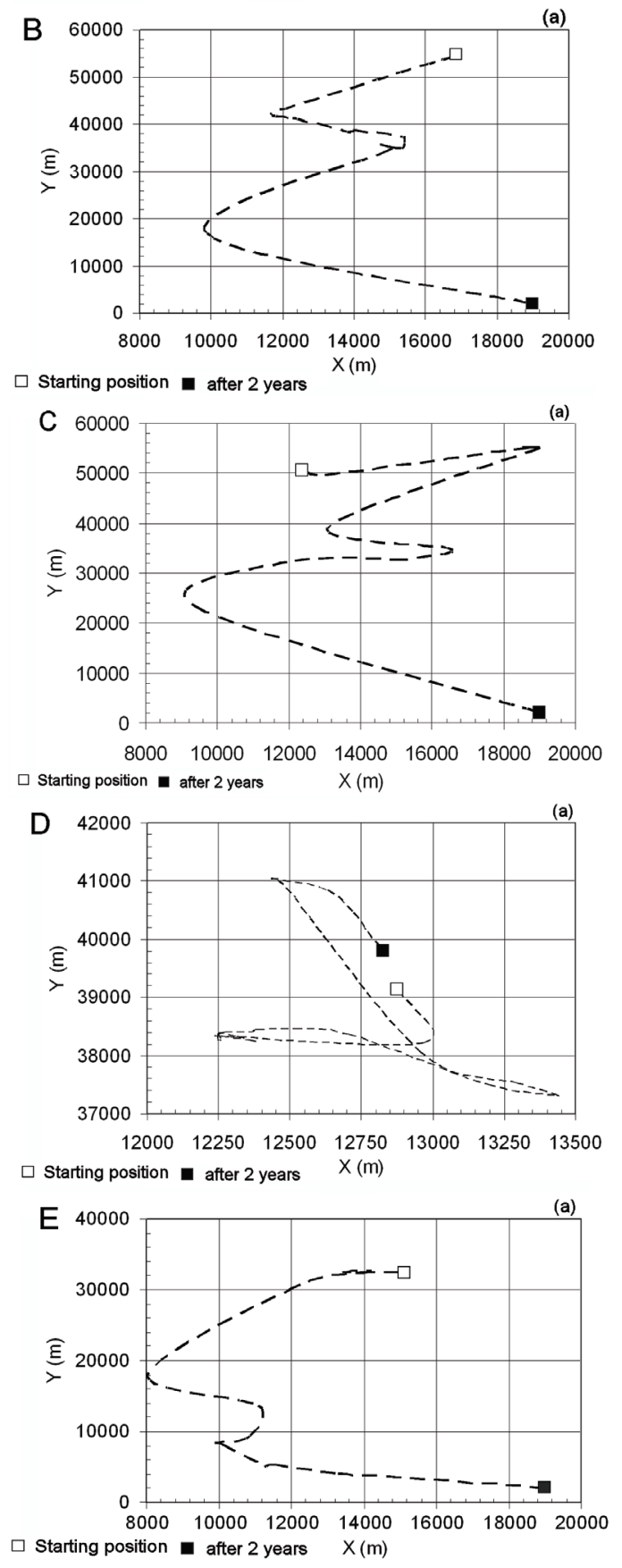
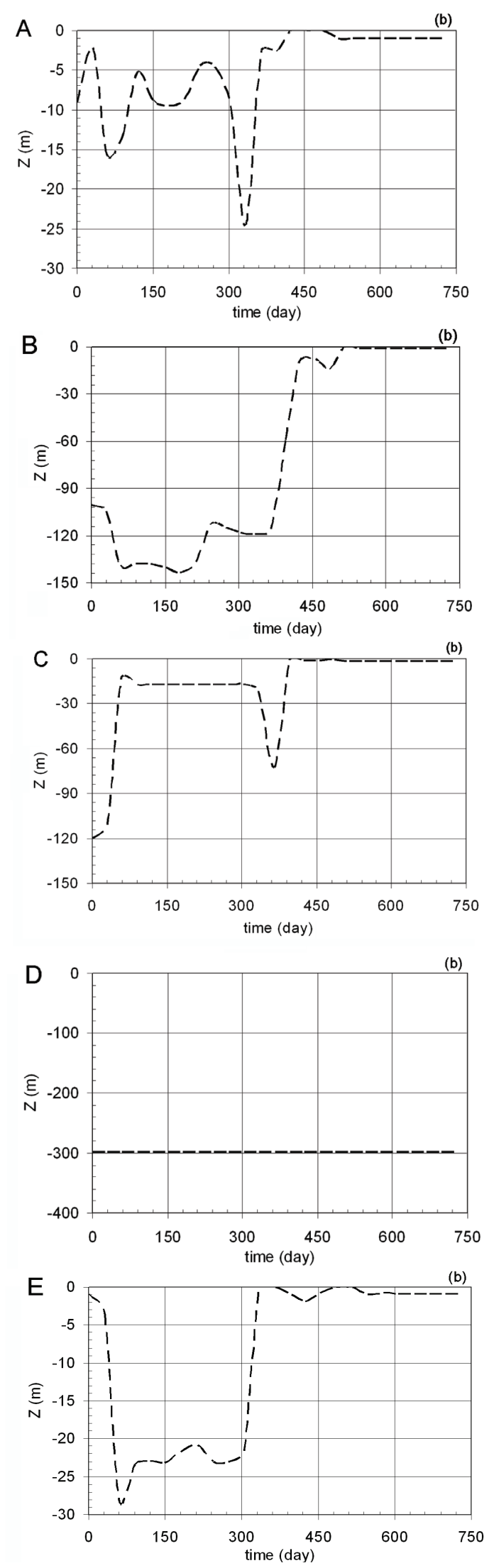

Fig. 8. Horizontal (a) and vertical (b) movement of marker M5 (A), M31 (B), M34 (C), M48 (D), M67 (E). 
3) Of the 19 environmental markers with a starting position more than $130 \mathrm{~m}$ below the free surface, only the one labelled M34 reached the area of the outflowing Ticino; its initial position at the level of the River Maggia delta probably affected its progress. Its residence time was around 400 days. Of the others: markers M40, M41, M42, M 44, M46, M47, M48 tended to return to their initial position after more or less wide-ranging up and down movements through the water body. The movements of M36 and M37 were very short. M43, M45, M50 were lost from the calculation domain (numerical accidents). M36, M37 and M39 tended to move in a northerly direction. The others covered about one third of their nominal distance from the South but with more or less the same vertical position as they started with.

The stationary behaviour of this group of markers may be attributed to the fact that they were placed in the lake hypolimnion, an isolated and stable zone where water movements do not generally exceed one centimeter per second, except during certain events, mostly in winter, connected with the convective mixing or other mechanisms of oxygenation of the deepest layer. It has been shown that these mechanisms are not able to transfer masses of water from the bottom to the surface, and above all, during the two years of the simulation no water penetrated the layers of the hypolimnion (Ambrosetti et al. 2010).

4) Only 6 of the 22 tributary markers can be regarded as having exited the lake with the water of the outflowing Ticino: M53-M54 (from the Vevera), M56 (second marker from the Erno), M67-M68 (Tresa), M72 (second marker from the Bardello). The residence time values were around 2 years for Vevera and Erno, and around 350 and 400 days for Tresa and Bardello respectively. Markers M57 and M58 from the Toce covered almost $80 \%$ of their nominal distance to the outlet. The others showed varying behaviours: the trajectories of markers M59-M60 (S. Bernardino) and M63-M64 (Maggia) tended to move in a SW direction, in contrast to M55 (Erno, first marker), M65-M66 (Verzasca), M69 (Boesio, first marker), M71 (Bardello, first marker), which travelled in a NE direction; M61 and M62 (Cannobino) both moved $\mathrm{W}$ but one towards $\mathrm{N}$ and the other towards S. Finally, the first marker of the Ticino tributary, M51, covered more than one-half of its nominal N-S distance to the outlet, while the second Ticino marker, M57, showed only a movement towards W.

The striking differences in behaviour between the tributary markers, even between single pairs, can be interpreted only in the light of the diverse thermal characteristics of the inflowing waters and the water present in the lake.

A first observation is that all the exiting markers had their starting position in the mouth of tributaries draining basins with low altitudes, i.e. with water whose temperature allows it to penetrate only the most superfi- cial levels of the lake. In contrast, the tributaries flowing down from basins with higher mean altitudes, specifically the inflowing Ticino, the Maggia, and the Toce, may carry a load of glacial silt, which increases their density and means that they penetrate deeper layers of the lake. Nevertheless, these markers do not in their subsequent route through the lake exceed a depth of 100 $\mathrm{m}$, probably because they mix with the receiving water. Confirmation of the fact that they do not reach the lake bottom is provided by the fact that in the two years of the simulation no increase of oxygen was recorded in the hypolimnion; on the contrary, the oxygen decreased (Ambrosetti et al. 2010).

As for the different behaviour noted between single pairs from the same tributary mouth, the fact that they were inserted at two different depths $(1$ and $7 \mathrm{~m})$ may have meant that each time they were inserted into streamlines with completely different dynamic characteristics, determined not only by the different penetration depths of the inflowing waters (referred to above), but also by local morphological conditions.

\section{CONCLUSIONS AND WORK IN PROGRESS}

The essence of the results of this study may be briefly summarized as follows:

a) much of the water arriving in the lake from tributaries and/or from depths from 0.0 to around $50-70 \mathrm{~m}$ below the free surface has probable residence time values between 250 days and 2 years or more;

b) the water flowing below $150-180 \mathrm{~m}$ shows some movement but is very unlikely to rise vertically;

c) we can make no general hypothesis as to the fate of the water flowing in the intermediate zone.

These first conclusions about the residence time of Lago Maggiore water are fully confirmed by the mechanisms of mixing and of deep water oxygenation described by Ambrosetti et. al. $(2007,2010)$ : in the winter, the water in the top layer (generally $100-150 \mathrm{~m}$, in conformity with the convective activity of the last 40 years) is able to circulate freely. In contrast, the water in the deepest layers remains isolated, though it may have a low degree of internal movement, and can be regarded as "still". The fate of the intermediate water mass is linked to the fact that this water undergoes the impact from year to year of the vertical winter mixing, and its renewal time depends on the extent to which it is involved in the circulatory system.

Confirmation of these observations also comes from an analysis of the vertical distributions of thermal stability, which can show the distinct separation between upper mixed layers, upper hypolimnion and deep hypolimnion (Ambrosetti et al. 2010).

However, the study described here is merely the introduction to a wider study on the possibility of using the Eulerian-Lagrangian methods of CFD (Computational Fluid Dynamics) to evaluate the hydraulic resi- 
dence time of a large southern Alpine lake like Lago Maggiore.

The study underlines both the potential and the difficulties involved in this approach. Whatever its degree of sophistication, from a theoretical standpoint a 3D mathematical model always offers a huge number of investigation possibilities. This can easily be deduced from the structure of the equations discussed in section 3 , which represents a model of medium complexity; further comments are unnecessary.

Any difficulties will lie in the actual possibility of exploiting the potentiality of these models at a sufficiently high degree of precision. From a practical point of view this means that the number of markers used will have to be large enough to yield statistically significant results, on a sufficiently fine discretization of the waterbody. This may be easily deduced from the quite marked differences observed in the trajectories of particles with relatively close starting positions, and in particular between the two particles associated with the same tributaries.

In consideration of these remarks, research currently in progress is as follows: a) an extension of the simulations described above to a period of more than 4 years; b) a new series of comparisons with more detailed discussion and 200 markers. The new discrete model and the starting position of the Lagrangian particles have been adjusted on the basis of the results described in the preceding section.

\section{ACKNOWLEDGEMENTS}

We are thankful to our colleagues Oscar Ravera and Salvatore Triosi for the insightful review of this work.

\section{REFERENCES}

Ambrosetti, W. \& L. Barbanti. 1999. Deep water warming in lakes; an indicator of climatic change. J. Limnol., 58(1): 1-9.

Ambrosetti, W. \& L. Barbanti. 2002. Phisycal limnology of italian lakes. 2. Relationship between morphometric parameters, stability and Birgean work. J. Limnol., 61(2): 159-167.

Ambrosetti, W.\& N. Sala. 2008. Climatic memory of 5 italian deep lakes: secular variations. Chaos and Complexity Letters, 3(2): 211-214.

Ambrosetti, W., L. Barbanti \& E.A. Carrara. 2007. Riscaldamento delle acque profonde nei laghi italiani. In: Carli, B., G. Cavarretta, M. Colacino \& S. Fuzzi (Eds). Clima e cambiamenti climatici. Le attività di ricerca del CNR. Roma: 601-604.

Ambrosetti, W., L. Barbanti \& E.A. Carrara. 2010. Mechanisms of hypolimnion erosion in a deep lake (Lago Maggiore, N. Italy). J. Limnol., 69(1): present issue.

Ambrosetti, W., L. Barbanti \& N. Sala. 2003. Residence time and physical processes in lake. International Conference on Residence Time in Lakes: Science, Management, Education. September $29^{\text {th }}$ - October $3^{\text {rd }}$ Bolsena Viterbo, $J$. Limnol., 62 (Suppl. 1): 1-15.

Ambrosetti, W., L. Barbanti, E.A. Carrara \& A. Rolla. 2007. Indagini sull'ambiente pelagico. Limnologia fisica. In: C.N.R. Istituto per lo Studio degli Ecosistemi. Ricerche sull'evoluzione del Lago Maggiore. Aspetti limnologici., Campagna 2007 e rapporto quinquennale 2002-2007.
Commissione Internazionale. per la protezione delle acque italo-svizzere: $37-44$.

Anderson, L.F. 1954. Instrumentation for mass-transfer and energy budget studies, in water-loss investigation: Lake Hefner studies. U.S. Geological Survey Professional Paper, 269: 35-45.

Barbanti, L. \& A. Carollo. 1965. Dinamica dei processi circolatori nel bacino meridionale del Lago Maggiore. Mem. Ist. ital. Idrobiol., 19: 9-80.

Bird, R.B., W.E. Stewart \& E.N. Lightfoot. 1960. Transport Phenomena. J. Wiley \& Sons, New York: 780 pp.

Bolin, B. \& H. Rodhe. 1973. A Note on the concepts of age distribution and transit time in natural reservoirs. Tellus, 25: 58-62.

Castellano, L., W. Ambrosetti \& N. Sala. 2008. About the use of compututional fluid dynamic (CFD) in the framework of physical limnological studies on a Great Lake. In: Orsucci F. \& N. Sala (Eds), Reflexing Interfaces. Information Science Reference. Hershey, New York, London: 257-277.

Castellano, L., A. Colombo \& A Tozzi. 1977. Modello numerico-differenziale per la dispersione of calor e inquinanti in ambienti marini. Rapporto Tecnico CALISMA/MATEC preparato per ENEL-CRTN, Milano.

Delhez, E.J.M. \& E. Deleersnijder. 2006. The Boundary layer of the residence time field. Ocean Dynamics, 56: 139-150.

Dinelli, G. \& A. Tozzi. 1977. Three-Dimensional modelling of the dispersion of pollutants in mediterranean coastal waters. Proceedings of XVII Int. Congress of IAHR, August 1977, Baden Baden (Germany): 52-61.

Döös, K. \& A. Engqvist. 2007. Assessment of water exchange between a discharge region and the open sea. A comparison of different methodological concepts. Estuarine, Coastal and Shelf Science, 74: 585-597.

George, D.G. \& M.A. Hurley. 2003. Using a continuous function for residence time to quantify the impact of climate change on the dynamics of thermally stratified lakes. $J$. Limnol., 62 (Suppl. 1): 21-26.

Herman, J., J. Shen \& J. Huang. 2007. Tidal flushing characteristics in Virginia's Tidal Embayments. Tech. Rept., Virginia Department of Environmental Quality, Center for Coastal Resources Management, Virginia Institute of Marine Science, Gloucester Point, Virginia (USA): 76 pp.

Huber, W.C., D.R.F. Harleman \& P.J. Ryan. 1972. Temperature prediction in stratified reservoirs. ASCE, Journal of the Hydraulics Division, 98(HY4): 645-666.

Ji, Z.G. 2008. Hydrodynamics and Water Quality: Modeling Rivers, Lakes, and Estuaries. Wiley-Interscience, Hoboken, New Jersey: 676 pp.

Jouon, A., P. Douillet, S. Ouillon \& P. Fraunié. 2006. Calculations of hydrodynamic time parameters in a semi-opened coastal zone using a 3D hydrodynamic model. Continental Shelf Research, 26: 1395-1415.

Laval, B., J. Imberger, B.R. Hodges \& R. Stocker. 2003. Modeling circulation in lakes: spatial and temporal variations. Limnol. Oceanogr., 48(3): 983-994.

León, L.F., D.C.L. Lam, W.M. Schertzer \& D.A. Swayne. 2006. A 3D hydrodynamic lake model: simulation on Great Slave Lake. Proceedings International; Modelling and Software Society Biennial Conference. Burlington, Vermont, July 9-13, 2006.

Liu, W.C., W.B. Chen, J.T. Kuo \& C. Wu. 2007. Numerical determination of residence time and age in a partially mixed estuary using three-dimensional hydrodynamic model. Continental Shelf Research, 28(8): 1068-1088.

Loga-Karpinska, M., K. Duwe, C. Guilbaud, M. O'Hare, U. Lemmin, L. Umlauf, E. Hollan, B. Wahl, V. Podsetchine, A. Peltonen, M. Filocha \& P. Mahnke. 2003. D24: Realistic residence times studies. Integrated Water Resource Management for Important Deep European Lakes and their Catchment Areas, Eurolakes. Tech. Rept. FP5Contract No.: EVK1-CT1999-00004: 54 pp. 
Lucas, L.V., J.K. Thompson \& L.R. Brown. 2009. Why are diverse relationships observed between phytoplankton biomass and transport time? Limnol. Oceanogr., 54(1): 381-390.

Martin, J.L. \& S.C. McCutcheon. 1999. Hydrodynamics and transport for water quality modeling. Taylor \& Francis Inc., New York, Part I: 14-16.

McGuire, K.J.\& J.J. McDonnell. 2006. A review and evaluation of catchment transit time modeling. J. Hydrol., 330: 543-563.

Monsen, N.E., J.E. Cloern, L.V. Lucas \& S.G. Monismith. 2002. A comment on the use of flushing time, residence time, and age as transport time scales. Limnol. Oceanogr., 47(5): 1545-1553.

Oliveira, A. 2006. Residence times: concepts, methodologies and applications. LNEC (Laboratório Nacional de Engenharia Civil), Lisboa (Portugal): $17 \mathrm{pp}$.

Piontelli, R. \& V. Tonolli. 1964. Il Tempo di residenza delle acque lacustri in relazione ai fenomeni di arricchimento in sostanze immesse, con particolare riguardo al Lago Maggiore. Mem. Ist. ital. Idrobiol., 17: 247-266.
Rossi, G., V. Ardente, F. Beonio-Brocchieri.\& E. Diana. 1975. On the calculation of the mean residence time in monomictic lakes. Hydrological Sci. Bulletin, XX(4): 575-580.

Rueda, F.J. \& E.A Cowen. 2005. Residence time of a freshwater embayment connected to a large lake. Limnol. Oceanogr., 50(5): 1638-1653.

Sheldon, J.E. \& M. Alber. 2002. A comparison of residence time calculations using simple compartment models of the Altamaha River Estuary, Georgia. Estuaries, 25 (6B): 1304-1317.

Shen, J. \& L. Haas. 2004. Calculating age and residence time in the tidal York River using three-dimensional model experiments. Estuarine, Coastal and Shelf Science, 61(3): 449-461.

Waugh, D.W, M.K. Vollmer M.K., R.F. Weiss, T.W.N. Haine \& T.M. Hall. 2002. Transit time distributions in Lake Issyk-Kul. Geophysical Research Letters, 29(24): 84.1-84.4.

Wilde, J., M. Mierzwa \& B. Suits. 2006. Using particle tracking to indicate delta residence time. California Water and Environmental Modeling. Forum 2006, Annual Meeting, February $28^{\text {th }}$ - March $2^{\text {nd }} 2006$, Pacific Grove, California.

\section{A P P E N D I X}

Nomenclature

\begin{tabular}{|c|c|c|c|}
\hline & Italic Symbols & & Greek Symbols \\
\hline$C_{p}$ & Heat Capacity; $\left[L^{2} / t^{2} T\right]$ & $\alpha_{\sigma}$ & Turbulent Thermal Diffusivity in $\sigma$-direction, $\sigma=x, y, z ;\left[L^{2} / t\right]$ \\
\hline$g$ & Gravity Acceleration; $\left[L / t^{2}\right]$ & $\Gamma$ & Mass Diffusivity $\left[L^{2} / t\right]$ \\
\hline $\bar{h}$ & Layer Thickness; $[L]$ & $\eta$ & Elevation of the Free Surface; $[L]$ \\
\hline$p$ & Pressure; $\left[M / L t^{2}\right]$ & $\mu_{\sigma}$ & Turbulent Viscosity in $\sigma$-direction, $\sigma=\mathrm{x}, \mathrm{y}, \mathrm{z} ;\left[M / L / t^{2}\right]$ \\
\hline$q$ & Conduction and Radiation Heat Fluxes; $\left[M / t^{3}\right]$ & $\rho$ & Water Density $\left[M / t^{3}\right]$ \\
\hline$q_{z}$ & Net Heat Flux in z-direction, divided by $\rho C_{p} ;[L T / t]$ & $\underline{\tau}$ & Stress Tensor $\left[M / L / t^{2}\right]$ \\
\hline$S$ & Water Salinity; $[-]$ & $\tau_{h}$ & Hydraulic Residence Time $[t]$ \\
\hline$S_{M}$ & $\begin{array}{l}\text { Internal Source of Mass } \\
\text { per surface unit and time unit divided by } \rho ;[L / t]\end{array}$ & $\tau_{\sigma \varsigma}$ & Turbulent Stress Tensor in $\sigma \varsigma$ plane $(\sigma, \varsigma=x, y, z) ;\left[M / L / t^{2}\right]$ \\
\hline$S_{M_{L}}$ & $\begin{array}{l}\text { Net Source of Mass (by rain, runoff, evaporation) } \\
\text { per surface unit and time unit divided by } \rho ;[L / t]\end{array}$ & $\omega$ & Mass Fraction of the tracer species [-] \\
\hline$S_{T}$ & $\begin{array}{l}\text { Internal Source of heat per surface unit and time unit } \\
\text { divided by } \rho C_{p} ;[L T / t]\end{array}$ & & \\
\hline$S_{T, M_{L}}$ & $\begin{array}{l}\text { Net Source of heat (by rain, runoff, evaporation) } \\
\text { per surface unit and time unit, divided by } \rho C_{p} ;[L T / t]\end{array}$ & & \\
\hline$S_{u}$ & $\begin{array}{l}\text { Internal Source of } x \text {-Momentum } \\
\text { per surface unit and time unit; }\left[M / L t^{2}\right]\end{array}$ & & \\
\hline$S_{v}$ & $\begin{array}{l}\text { Internal Source of } y \text {-Momentum } \\
\text { per surface unit and time unit; }\left[M / L t^{2}\right]\end{array}$ & & \\
\hline$t$ & Time; $[t]$ & & \\
\hline$T$ & Temperature; $[T]$ & & \\
\hline$\underline{u}$ & Water Velocity Vector; $[L / t]$ & & \\
\hline$u$ & Water Velocity in $\mathrm{x}$-direction; $[L / t]$ & & \\
\hline$U_{\text {wind }}$ & Wind Strength; $[L / t]$ & & \\
\hline$U_{\text {wind }, \sigma}$ & Wind Velocity in $\sigma$-direction, $\sigma=x, y$; $[L / t]$ & & \\
\hline$v$ & Water Velocity in $y$-direction $[L / t]$ & & \\
\hline$w$ & Water Velocity in $z$-direction $[L / t]$ & & \\
\hline$\underline{x}_{p}$ & Particle Position $[L]$ & & \\
\hline$x$ & Coordinate along horizontal $x$-direction $[L]$ & & \\
\hline$v$ & Coordinate along horizontal $y$-direction $[L]$ & & \\
\hline$z$ & Coordinate along vertical $z$-direction $[L]$ & & \\
\hline
\end{tabular}

Received: June 2009

Accepted: September 2009 